\title{
Adapting practice-based philosophy of science to teaching of science students
}

Sara Green ${ }^{1 *}$, Hanne Andersen ${ }^{1}$, Kristian Danielsen ${ }^{1,2}$, Claus Emmeche ${ }^{1}$, Christian Joas ${ }^{1,3}$, Mikkel Willum Johansen ${ }^{1}$, Caio Nagayoshi ${ }^{4}$, Joeri Witteveen ${ }^{1} \&$ Henrik Kragh Sørensen ${ }^{1}$

${ }^{1}$ Section for History and Philosophy of Science, Department of Science Education, University of Copenhagen, Denmark. *Author of correspondence: sara.green@ind.ku.dk

${ }^{2}$ Center for Science Studies, Department of Mathematics, Aarhus University, Denmark.

${ }^{3}$ Niels Bohr Archive, Copenhagen, Denmark.

${ }^{4}$ Escola Vera Cruz and Colégio São Luís, São Paulo, Brazil.

\begin{abstract}
The "practice turn" in philosophy of science has strengthened the connections between philosophy and scientific practice. Apart from reinvigorating philosophy of science, this also increases the relevance of philosophical research for science, society, and science education. In this paper, we reflect on our extensive experience with teaching mandatory philosophy of science courses to science students from a range of programs at University of Copenhagen. We highlight some of the lessons we have learned in making philosophy of science "fit for teaching" outside of philosophy circles by taking selected cases from the students' own field as the starting point. We argue for adapting philosophy of science teaching to particular audiences of science students, and discuss the benefits of drawing on research within science education to inform curriculum and course design. This involves reconsidering teaching resources, assumptions about students, intended learning outcomes, and teaching formats. We also argue that to make philosophy of science relevant and engaging to science students, it is important to consider their potential career trajectories. By anticipating future contexts and situations in which methodological, conceptual, and ethical questions could be relevant, philosophy of science can demonstrate its value in the education of science students.
\end{abstract}

Keywords: Teaching philosophy of science; Case-based teaching; Philosophy of science in practice; Integrated history and philosophy of science; Science didactics; Implied student 
This is a preprint of a paper to appear in a topical collection in the European Journal of Philosophy of Science, on Teaching philosophy of science to Students from Other Disciplines.

\section{Adapting philosophy of science to teaching of science students}

Practice-oriented philosophers of science have emphasized the need to increase the relevance of philosophy of science for science and society (Ankeny et al. 2009; SPSP Mission statement; Soler et al. 2014). This aim is increasingly pursued through philosophical field work in scientific laboratories and collaborations with scientists (Brister and Frodeman 2020; Laplane et al. 2019). But another important avenue for increasing scientific and societal relevance is through teaching science students. Just as practice-orientation in research requires changes in focus and method, the didactic transposition of philosophy of science to science students requires adapting what and how we teach. We offer reflections and suggestions towards this end, based on our experience since 2005 with teaching mandatory courses in philosophy of science to undergraduate students enrolled in BSc programs at University of Copenhagen.

Philosophy of science courses of 7,5 ECTS credits are mandatory for all university students in Denmark. ${ }^{1}$ These courses are listed on the curriculum as "philosophy of [scientific discipline]". This signals that the courses are not intended as generic courses for students from multiple disciplines (cf. Grüne-Yanoff 2014), but instead have the purpose of promoting critical philosophical reflection through engagement with the subject matter of the specific program. One important reason is that the study programs in Denmark differ from university-level educational programs in many other countries, such as the US, by requiring students to specialize in a particular discipline from the outset. While national guidelines for philosophy of science courses exist, a critical task in our course design is to adapt the content and format of our teaching to increase the relevance to students in specific science programs. This involves considerations about which topics are relevant to specific groups of students, and how to best teach these.

Scholars before us have encouraged philosophers of science to critically reflect on whether their own topics of professional interest are equally well-suited for teaching scientists and science students. For example, Grüne-Yanoff (2014) argues that some philosophical topics are not equally relevant for science students. Boniolo and Campaner (2020) have similarly emphasized the need to tailor the teaching of philosophy of science to the needs of students or practitioners within the life and health sciences. This paper provides additional support for these views and pushes further towards practice-orientation by considering how we should teach in relation to science students'

\footnotetext{
${ }^{1}$ European Credit Transfer System (ECTS) was designed to increase the comparability of courses and study programs across European higher education. A year of study in European higher education corresponds to 60 ECTS. A 7,5 ECTS corresponds to 206 hours of work.
} 
This is a preprint of a paper to appear in a topical collection in the European Journal of Philosophy of Science, on Teaching philosophy of science to Students from Other Disciplines.

modes of study and specific educational contexts. We do so by emphasizing the benefits of casebased teaching and active learning approaches (see also Prince and Felder 2006; Terry 2012; Bursten and Finkelstein 2018). Case-based active teaching involves alternating between teacherstructured scaffolding and student-centered work on concrete cases within their own discipline (ElHani et al. 2020). Our aim is not to conduct a systematic review of the case-based approach, compared to other alternatives. Rather, we provide suggestions for how this approach can be used in philosophy of science courses, by introducing abstract philosophical topics and concepts in connection to cases that already interest the students. The paper offers reflections on the background for this choice, reports on our experiences, and provides suggestions for cases that we invite readers to try in their own teaching, when relevant.

As our starting point, we take an analytical concept from science education called the “implied student" (Ulriksen 2009). Similar to Iser's (1984) concept of the "implied reader" in the context of literary theory, the implied student refers to the tacit assumptions about students to which both teachers and students try to align their activities. As an analytical tool, the implied student not only serves to expose presuppositions we have about students in structuring teaching, but also helps to show how "structure and mode of teaching are dependent on students being willing and able to comply with the structure" (Ulriksen 2009). It highlights how the space for learning is mutually constrained by the implicit expectations of teachers and by the ability of students to recognize and meet those expectations. Ulriksen uses the concept to reflect on academic training in disciplinary educational structures (Kuhn 1962/1970) and to consider the academic socialization involved in education, which involves a "hidden curriculum" of social rules (Jackson 1968/1990). We find the concept useful as a reminder that any course design reflects assumptions about the students - assumptions which may need to be reconsidered when adapting philosophy of science courses to science students. In particular, we cannot assume that science students will be interested in all the canonical themes of traditional philosophy of science courses, nor that they are familiar with the teaching format or expectations of such a course.

The science students we encounter in the specialized BSc programs are often confused about what to expect from a philosophy of science course. Since content and form typically differ greatly from other courses in their curriculum, a lack of clarity about the intended learning outcomes (ILOs) can lead to frustration and reduced motivation. Attempts to address this problem can benefit from critically examining students' expectations, those held personally by students and through their (implicit) expression in the study program (Ulriksen 2009). The course design should fit with 
This is a preprint of a paper to appear in a topical collection in the European Journal of Philosophy of Science, on Teaching philosophy of science to Students from Other Disciplines.

students' ideas about what it means to study and what they perceive as relevant for their current and future practice. Moreover, teachers should make the expectations and learning objectives of philosophy of science courses clear to students, e.g., by presenting concrete examples of how philosophy of science can deepen important discussions within or about their own field.

An oft-stated aim of philosophy of science courses is to make science students better scientists, i.e., to make science students more critically reflective of their own scientific research practices (Price 2012; Grüne-Yanoff 2014; Boniolo and Campaner 2020). We are supportive of this claim, which also motivates our own teaching. At the same time, closer consideration of the implied student in this approach calls for further reflection on this assumed aim. First, attention to science "in practice" reveals a variety of research approaches, which broaden and blur the category of "better scientist". Second, science students today have educational goals that differ from, and extend beyond, preparation for a research career. Assuming that all science students want to become researchers may alienate those who are instead aiming to pursue careers in industry, policy, consulting, or teaching. Thus, it is important to consider how philosophers of science can be designed in a way that is relevant for the existing diversity of study practices and anticipated career trajectories.

In the following, we explain how we adapt the teaching of philosophy of science to science students to meet their needs. Our suggestions should be understood within the context of an educational system in which philosophy of science courses are mandatory, and we therefore begin by putting our own teaching practices in context. Regardless of this special context, we hope that reflecting on our experiences are useful for others who teach philosophy of science to science students. We clarify the background for our choice of case-based teaching in Section 3 and provide examples of cases taught in Section 4. Section 5 offers concluding remarks.

\section{Teaching philosophy of science in Denmark}

In a European setting, the relevance of philosophy of science for science students was recognized by the European Qualifications Framework for Lifelong Learning in 2008, which included "critical understanding of theories and principles" and "critical awareness of knowledge issues in a field" as learning outcomes for bachelor's and master's degrees, respectively (European Commission 2008, p. 18). However, no general overview exists of how this part of the framework has been implemented across the European Union that spans quite different systems for higher education. 
This is a preprint of a paper to appear in a topical collection in the European Journal of Philosophy of Science, on Teaching philosophy of science to Students from Other Disciplines.

In Denmark, our local setting, a 2003 parliamentary debate prompted an agreement between the national universities and the Ministry of Education to introduce a mandatory philosophy of science course into all bachelor programs. The intent was to provide students with an opportunity to "qualify their disciplinary specialization by contextualizing it in a larger perspective" and thus to "connect disciplinary questions with interesting and relevant issues of a more general character" (translated from Andersen et al. 2018, p. 24). The courses should therefore include not only philosophy of science in a strict sense, but also elements that could give students an understanding of their field within society, including the social and ethical responsibility of scientists. Hence, despite their name, the courses were expected to also include history and sociology of science as well as ethics.

National guidelines for philosophy of science courses have been implemented locally at University of Copenhagen through a generic set of minimal ILOs that all mandatory philosophy of science courses at the Faculty of Science need to fulfill. Importantly, these ILOs differ from traditional philosophy of science courses designed for philosophy students. To illustrate how, Table 1 lists the differences in ILOs for philosophy students (left column) and science students (right column) at University of Copenhagen. Table 1 shows that in the course for philosophy students, the emphasis is on acquiring competences to provide a systematic analysis of philosophical positions and their historical contexts. This reflects the structuring of teaching according to the assumption that the "implied student" is already interested in, and familiar with, central positions and debates within philosophy. This cannot be assumed for science students. However, science students will be more familiar with advanced methods and concepts in their respective scientific discipline, which can provide an entry for case-based discussions that draw on these experiences (more on this in Sections 3 and 4). In other words, it is important to keep in mind how the "implied student" may differ in the two contexts.

In alignment with these aims, we teach philosophy of science courses targeting students from actuarial science, biochemistry, biology, chemistry, computer science, geography, geology, machine learning and data science, mathematics, mathematics-economy, nanoscience, physics, and sports science at University of Copenhagen. ${ }^{2}$ Whereas it is an important aim in the course for philosophy students to describe the different modes of knowledge generation in the broader spectrum of the natural sciences, the social sciences, and the arts, we aim to further adapt the

\footnotetext{
${ }^{2}$ For examples of course descriptions, see: https://kurser.ku.dk/course/nndb12002u/; https://kurser.ku.dk/course/nndb19000u; https://kurser.ku.dk/course/NNDB19006U; https://kurser.ku.dk/course/NNDB19002U; https://kurser.ku.dk/course/nndb19005u.
} 
This is a preprint of a paper to appear in a topical collection in the European Journal of Philosophy of Science, on Teaching philosophy of science to Students from Other Disciplines.

generic template to the respective target groups through the design of different courses for students from each discipline. ${ }^{3}$ While all of our courses contain some generic elements (such as responsible conduct in research and practice), we make an effort to design teaching around cases that emphasize the epistemological, ethical, and social aspects of the specific discipline, as well as the institutional history relevant to that discipline.

\footnotetext{
${ }^{3}$ The point is not that philosophy of the social sciences or arts are not relevant to (some) science students, but rather that the relevance should be evaluated on the basis of the specific educational context. For example, our course for sports science students also includes philosophy of social science and humanities, because many students specialize in sociology, history, or areas that require the use of qualitative methods.
} 

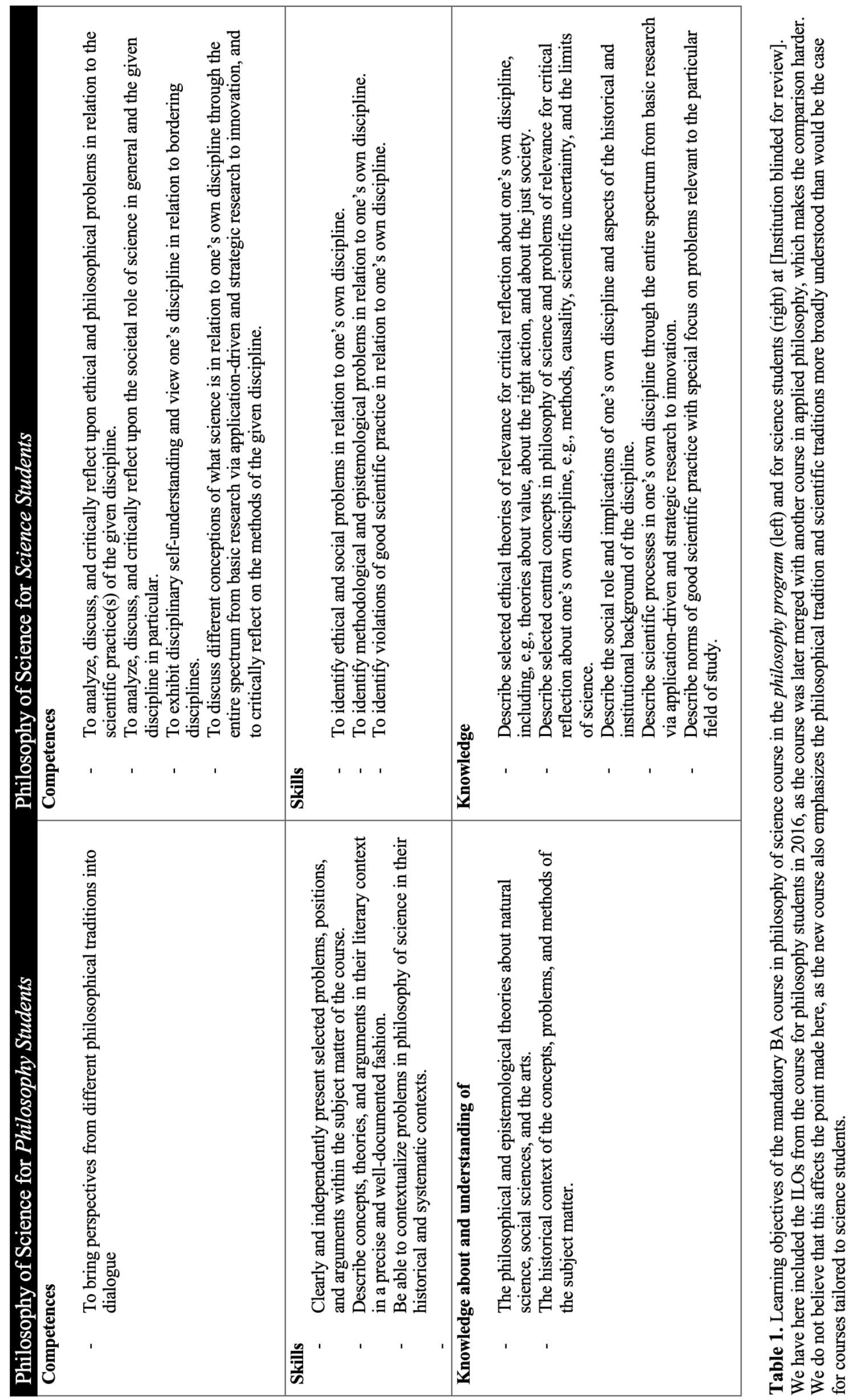
This is a preprint of a paper to appear in a topical collection in the European Journal of Philosophy of Science, on Teaching philosophy of science to Students from Other Disciplines.

In summary, our courses are intended to target specific scientific disciplines, and are all situated at the intersection of philosophy of science, history of science, science studies, and ethics. From this position, they aim to prompt critical, philosophical reflection on the specific discipline of study, its central questions and issues, its history, and its role in society. In the following sections, we illustrate some of the considerations we face when designing and teaching these courses and reflect upon the benefits of taking historical and contemporary cases from the specific fields as starting points for philosophical analysis.

\section{Reconsidering content and teaching format}

How do we ascertain which topics are engaging and relevant for science students in particular disciplines? In our experience, dialogues with students and science colleagues help make the courses more relevant and engaging. In recent years, textbooks in philosophy of science have emerged that are more accessible to science students in general (e.g., Giere et al. 2006; Potochnik et al. 2018), and to specific groups of science students (e.g., Kampourakis and Uller 2020). Yet, we contend that the relevance of some classical philosophical topics should primarily be considered in relation to how these are taught in the context of a specific science program.

\subsection{Teaching traditional topics in new ways}

One example of a highly abstract topic primarily of interest to philosophers is the scientific realism/antirealism debate (Grüne-Yanoff 2014). Philosophers of scientific practice have shown that this debate can be brought to bear on research practice by considering whether and how the aim of truth-seeking is relevant in particular scientific fields and circumstances (Chang 2012b; Currie 2018; Potochnik 2017). A similar approach can be adopted in teaching of philosophy of science. Rather than starting with the abstract philosophical debate on realism/antirealism, a more useful entry point would be to consider relevant discussions within science itself. An example is how scanning tunnelling microscopy (STM) gives us new ways to "see", manipulate, and think about phenomena at the scale of atoms (Toumey 2009). In our experience, students in physics and nanoscience can productively draw on their own experiences with advanced microscopy in a discussion of how understanding sometimes is facilitated through translation of numerical STM 
This is a preprint of a paper to appear in a topical collection in the European Journal of Philosophy of Science, on Teaching philosophy of science to Students from Other Disciplines.

data into highly idealized visual images, such as the famous "quantum corral" featured on the cover of Science, 262, 1993 (Crommie et al. 1993).

Another example, taken from the course we teach to geography students, is to introduce students to basic philosophical questions about laws, explanation, and idealization using a contemporary example of a "unified theory of urban living" (Bettencourt and West 2010).

Developed by physicists specializing in complex systems, this theory has been strongly criticized by geographers for its broad generalizations and law-like approach to answering geographical questions (O'Sullivan and Manson 2015). Cases like this allow students to familiarize themselves with philosophical themes without leaving their disciplinary home ground, thus providing a safe environment for engaging with novel kinds of questions.

The suggestion to reconsider the format, and not only the topic, is equally relevant when teaching ethics. Traditional ethical positions may be experienced as irrelevant to the students' own practice, if teaching primarily consists of rehearsing "long-standing and insoluble debates among long-dead men" (Bursten and Finkelstein 2018, p. 1). Of higher relevance to the students is the ability to identify hidden assumptions in ethical argumentation, as well as the capacity to discuss the implications of various views. Bursten and Finkelstein suggest using what they call boundary cases to confront students with examples that promote cognitive conflict. The aim is to compel students to examine unexpected ramifications and unwelcome consequences of their own viewpoints. We believe that these competences can be trained while also reestablishing the lost connection to more abstract theoretical frameworks in ethics.

To exemplify, [Author] has in collaboration with colleagues in sports science designed exercises inspired by previous masters' projects. Ethical frameworks were discussed in relation to concrete imaginative research projects, including an experimental intervention study on the effects of physical activity to reduce obesity among school children. The students were asked to identify possible ways in which the imagined research projects could harm participants, and to discuss which ethical positions may support such considerations (e.g., deontological ethics or utilitarianism). We found that by drawing on such examples, it is easier for students to recognise the relevance of abstract ethical principles (such as those guiding the Helsinki declaration or data protection laws) for their own practice. The exercise also promoted critical self-reflection on their own assumptions about the research topic. The students were further asked to draft interview questions of relevance for the study of obesity. After reading and discussing text material presenting different views on the topic, the students were surprised to discover that their questions revealed 
This is a preprint of a paper to appear in a topical collection in the European Journal of Philosophy of Science, on Teaching philosophy of science to Students from Other Disciplines.

implicit epistemic and normative assumptions about obesity and weight loss. This resonates with Bursten and Finkelstein's (2018) suggestion that critical reflection can be promoted through examples that uncover and productively challenge the student's own presuppositions.

The examples above illustrate the difference between what in science education is called deductive and inductive teaching strategies (Prince and Felder 2006). While the traditional (deductive) approach starts with the history of the philosophical debate and primarily uses cases as illustrations, inductive teaching takes concrete cases or the students' own practice as the starting point. Inductive strategies lend themselves naturally to active learning approaches. Active learning refers to a spectrum of student-centered approaches, ranging from very "open” approaches, where students formulate their own questions and design their own analysis, to teacher-structured activities involving a mixture of teacher instruction and group work (Terry 2012; Hartikainen et al. 2019). Active learning involves one or more phases of adidactic teaching (Brousseau 1997), where the teacher steps back to let the students work on cases or problems on their own. ${ }^{4}$ It is, however, important that teachers instruct and follow up on the exercises, as students may need guidance to see relevant connections to general concepts or themes (El-Hani et al. 2020). Since studies in science education have documented the benefits of active learning approaches (Prince 2004; Entwistle 2009; Freeman et al. 2014), we organize our teaching around cases that we expect to already interest the students (see Section 4 for further examples).

\subsection{Historical and contemporary cases}

We view case studies as concrete and authentic problem situations or stories that illustrate the complexity of scientific practice in a manageable way (Allchin 2013, pp. 39-40). Focusing on cases reawakens a classical debate in philosophy of science about the relation between particular cases and general lessons, as well as considerations about which cases are most fitting for this purpose. Our intention is not to use cases to make inductive inferences about science in general, ${ }^{5}$ but to use these iteratively as mediators between concrete examples and abstract analysis (Nersessian 1995; Chang 2012a). Cases can put philosophy of science into context, and make abstract theories more

\footnotetext{
4 The concept of adidactic teaching is used within the theory of didactic situations (TDS), where "activation" presents a central element of the teaching model illustrated here: https://obl.ku.dk/theme/tds-model/.

${ }^{5}$ Readers may be familiar with debates on whether and how one can move from individual cases to more general theory in psychoanalysis and in medicine (Forrester 2017), or whether inferences can be made in HPS from single cases to (normative) philosophical claims (cf. Pitt 2001; Burian 2001).
} 
This is a preprint of a paper to appear in a topical collection in the European Journal of Philosophy of Science, on Teaching philosophy of science to Students from Other Disciplines.

cognitively accessible to students (Herreid et al. 2012). Conversely, abstract philosophical theories and concepts can help deepen the understanding of concrete scientific cases, e.g., by introducing conceptual tools that highlight similarities and differences between cases.

Another debated topic is whether philosophical analysis should primarily examine contemporary or past science (see, e.g., Giere 1973; Burian 1977). One argument raised in this debate was that historical cases have a pedagogical advantage because they tend to be less complex than contemporary cases. In contrast, historians of science have warned against "pseudohistorical" presentations of historical cases that reconstruct scientific discoveries as the result of a straightforward scientific methodology (see Allchin 2013, chapters 4 and 5; Powers 2020). Such debates emphasize the importance of situating cases in their historical and contemporary scientific contexts, which places new demands on the historical and scientific literacy of philosophy of science teachers. It can be challenging for philosophy teachers to acquire the competences required to discuss scientific cases with science students specialized in the same field, or to make sure that the presentation of a case acknowledges relevant historical nuances. Yet, these challenges can be addressed by training in dual competences or by collaboration on teaching. Our courses are often taught by scholars with dual training in a scientific discipline and philosophy or history, or in philosophy and history of science. Some courses are also taught in collaboration with scientists from the students' discipline. In the latter case, it is important that both sides of the collaboration are capable of engaging in some detail with both the philosophical and the scientific literature involved, i.e., both parties should have what sometimes is referred to as "interactional expertise" (Collins and Evans 2002; Goddiksen 2014; Plaissance 2020).

Both contemporary and historical cases can be used to stimulate reflections on the characteristics of "science in the making", as opposed to teaching "ready-made science" (Latour 1987; Allchin 2013). Whereas textbooks used in teaching science often present what they take to be uncontroversial exemplar cases of explanations and problem solutions (Kuhn 1962/1970), contemporary and historical cases provide insights into the tentative and exploratory aspects of knowledge generation. But historical and contemporary cases also have distinct benefits and limitations. Allchin et al. (2014) make a useful comparison of the complementary merits and deficiencies of contemporary and historical cases. Contemporary examples of scientific controversies motivate student engagement through their "here-now" relevance, but are by definition unresolved and open-ended, and therefore not ideal for illustrating how controversies can be settled. Historical cases can be harder to relate to the current practice of the students, but they 
This is a preprint of a paper to appear in a topical collection in the European Journal of Philosophy of Science, on Teaching philosophy of science to Students from Other Disciplines.

can foster understanding of how various strategies have been used to manage uncertainties and errors in the past. We elaborate on these points below.

Reassessing historical episodes within their own field from an HPS perspective provides a good way to engage students and improve their understanding of their field's historical development. First, it can help correct misconceptions created by the way history is presented within the discipline itself. In addition, some characteristics of science that rarely get discussed in science courses can be analyzed in historical case studies, e.g., the social nature of science and the establishing of scientific consensus, failed theories or experiments, or the social, political and moral implications of science. In our experience, science students are very interested in these topics, as they have a direct relevance to their own experience. Historical cases can also "humanize" science by showing the contingent and chaotic process of discovery of even the greatest heroes, who have also run into dead ends on their way. This is an eye-opener to students who often struggle themselves when presented with problems to solve or phenomena to understand (Matthews 2015/1994; Allchin 2013; Allchin et al. 2014). ${ }^{6}$ Learning how failure and ignorance are integral elements of scientific practice can improve their confidence going forward, and also impact their own self-understanding and future career decisions (Firestein 2012; 2015).

In our courses, we also use existing and unresolved scientific controversies to stimulate reflection on how regulatory decisions often have to be taken in contexts of scientific uncertainty, and in situations where epistemic and ethical questions are intertwined. For instance, biology students are presented with scientific publications that have different views on whether fish and invertebrates can feel pain. They are asked to discuss the strengths and weaknesses of the methods and evidence presented for the respective claims, as well as the ethical implications of different views. This can lead to stimulating discussions on the possibility of conducting "crucial experiments" in this field and about the possibility of operationalizing seemingly irreducible and difficult concepts such as pain and (animal) sentience. Students are rarely encouraged to ponder such questions in their science courses, and philosophy of science courses can offer a welcome space for such reflections.

\footnotetext{
${ }^{6}$ A useful resource for teaching sociology, history, and philosophy of science is the SHiPS resource center: http://shipseducation.net, which contains teaching modules and exercises searchable by topic and level.
} 
This is a preprint of a paper to appear in a topical collection in the European Journal of Philosophy of Science, on Teaching philosophy of science to Students from Other Disciplines.

\subsection{Considering student trajectories}

Lastly, to reap the benefits of case-based teaching, an additional level of tailoring to students is required: Among, and even within, undergraduate programs, student profiles and future career plans vary enough to require reflection on how to make philosophical discussions relevant to all of them. All programs, of course, produce candidates for research — either in academic or industrial settings. But some programs also serve other markets, in particular upper secondary education, public administration, and the private sector. In the programs in mathematics at the University of Copenhagen, for instance, we know from directly asking students that some of them wish to become teachers, some to pursue research careers, and most to enter jobs in industry. ${ }^{7}$ Some course topics, such as the reliability of mathematical knowledge, are relevant to all mathematics students, while other topics, such as the historical development of mathematics as a discipline, may be less relevant to some (e.g., students identifying with industry careers). The variety of prospective career trajectories, therefore, should be taken into account when selecting topics and cases.

The diversity of student identities presents new challenges for philosophy of science teachers but also new opportunities for making philosophy of science relevant in multiple contexts. In science education, for instance, philosophy of science has been recognized as an important part of the training of science teachers (Scheffler 1971; Abd-El-Khalick 2005; Matthews 1994/2015), which connects to the widely accepted view that upper secondary school students should not only learn scientific concepts, but also about how scientific knowledge is produced ("nature of science", or NOS). This perspective has been historically tied to scientific literacy as a broad goal in science education (Hodson 2014), however, one of the main obstacles to effective inclusion of history and philosophy of science in secondary science classrooms is teachers' lack of subject knowledge and understanding of how it connects to the scientific content they must teach (Höttecke and Silva 2011). Thus, philosophy of science can help prepare teachers to convey a better-informed image of science to their students.

For example, philosophy of science courses can provide a forum for students to share and reflect upon their experiences conducting laboratory experiments or making field observations. This

\footnotetext{
${ }^{7}$ Recent graduate surveys show that about $23 \%$ of the science students are enrolled as $\mathrm{PhD}$ students within the first three years at University of Copenhagen, while about $56 \%$ report work in the private sector and about $10 \%$ teach in secondary school and adult education. The latter number varies greatly between different science programs, ranging from 3-50\%, which underscores the importance of considering student diversity at different levels. The graduate surveys are available at: https://kunet.ku.dk/arbejdsomraader/uddannelsesadm/quality-of-assurance/graduatesurveys/Sider/default.aspx.
} 
This is a preprint of a paper to appear in a topical collection in the European Journal of Philosophy of Science, on Teaching philosophy of science to Students from Other Disciplines.

can provide practical guidance for how to handle anomalous results in different situations, e.g., in teaching and research contexts where the aims of experiments may differ. Discussion of realistic and tangible case examples can also help them develop the sound judgment needed when the idealized norms of good scientific practice cannot be applied in simple and straightforward ways (Johansen and Christiansen 2020). Students are also often positively surprised to learn that their own experiences can be used to promote critical reflection on philosophy of science itself. For instance, discussion of the complexity of experimentation and observation can provide a more nuanced perspective on the ideal of reproducibility, which may differ depending on the circumstances and aims of experimentation in different fields (see also Leonelli 2018; Guttinger 2020).

Of course, a single course cannot be tailored to the individual interests of each student, and it is also important to build a common professional identity among the students, no matter their career path. But when planning a course, it is crucial to make informed choices to ensure the relevance of the course to the students; simply realizing that not all students wish to pursue academic careers may be eye-opening.

\section{Case-based teaching: Examples from our courses}

In hope of stimulating further discussion and collaboration on developing teaching materials, we present four examples of cases from our courses in further detail. This selection corresponds to the four competences described in the generic template for the learning outcomes (see Table 1, right).

\section{Case 1: Can algorithms predict student dropouts?}

In 2014, a student from University of Copenhagen wrote his master's thesis on the use of machine learning algorithms. As part of the thesis the student developed an algorithm that could predict if a student in upper secondary school would drop out with about $93 \%$ accuracy. The algorithm was trained on performance data and data related to gender, ethnicity and socio-economic background from 72.598 upper secondary students who had used the learning platform Lectio (Şara et al. 2015). MaCom, the company behind Lectio, had given the master student access to the performance data without consulting with the schools, and MaCom implemented the drop-out prediction algorithm as part of Lectio when it was developed. School administrators, however, protested that their students' 
This is a preprint of a paper to appear in a topical collection in the European Journal of Philosophy of Science, on Teaching philosophy of science to Students from Other Disciplines.

privacy had been violated, and the algorithm was removed from Lectio after a week (Møllerhøj 2015).

We use the case as a starting point for several important ethical discussions relating to mathematics and computer science. These include: The rights of data subjects (was it acceptable that MaCom used students' data without their consent?), algorithmic bias (the algorithm includes sensitive information such as gender and ethnicity, but can we know if its training has given it gender or other biases?), and the connection between epistemology and ethics (the utilitarian argument in favor of using the algorithm is confronted with uncertainties about how the algorithm works and affects the behavior of the teachers, students, and administrators interacting with it).

\section{Case 2: Risk assessment and scientific uncertainty}

To promote reflection on the societal role of science, several courses include exercises where students discuss how their field can inform risk assessment and political decision making. Biology students watch a video where different stakeholders discuss the results of a cohort study documenting a statistical association between prenatal exposure to a chemical preservative and reduced head circumference of male infants (Lassen et al. 2015). Students in the chemical sciences discuss the merits and problems of estimating toxicity of new chemical compounds from knowledge about structurally similar ones (Bschir 2017). And physics students discuss the earthquake in L'Aquila in 2009 as a case highlighting the difficult ethical and epistemological choices physicists have to face when they advise the public on the basis of incomplete or unclear data (Hall 2011). These cases illustrate that waiting for conclusive scientific evidence is often not an option. Students must therefore evaluate different types of evidence (and uncertainty) against the "inductive risks" of assessments that may under- or overestimate potential harm. The cases also raise discussions on whether and how to inform the general public about potential harm and scientific uncertainty, which is challenging in societal contexts where mistrust in science is a pressing concern (see also El-Hani et al. 2020).

\section{Case 3: "Functional" in biochemistry, chemistry, nanoscience.}

To address the learning goal of being able to "exhibit disciplinary self-understanding and view one's discipline in relation to bordering disciplines", students in a course for chemistry, biochemistry, and nanoscience discuss the notion of 'functional' from their respective backgrounds, engaging with both commonalities and differences. The case is preceded by brief introductions to 
This is a preprint of a paper to appear in a topical collection in the European Journal of Philosophy of Science, on Teaching philosophy of science to Students from Other Disciplines.

the history of the three fields, and is initiated with discussion exercises, asking the students to reflect upon a well-known concept from their field, and to contrast it with a seemingly similar concept in a neighboring field - in this case the chemical concept of a functional group, the biochemical concept of molecular function, and function in "nanomachines". The exercise starts out broadly, asking about the roles of these notions in research. The students are often puzzled by this question, albeit in different ways; nanoscience students may see molecular function as the workings of engineerable structures at the nanoscale, while biochemistry students are more interested in the evolution of macromolecular "active sites" than in functional groups. The question "Can the concept of ketone as a functional group be reduced to quantum chemistry or physics?" is then discussed and used to introduce the more general question of how scientific disciplines interact, not only from a positivist perspective on theory reduction, but also integrating contemporary views of disciplines as systems of practice with a variety of interactions (Chang 2015).

\section{Case 4: Disciplinary and professional identity in computer science}

To activate student reflections on the spectrum of science within their own discipline, the tutorials in philosophy of computer science start with an introductory exercise, with 25 students divided into five groups. Each group receives one of five short primary texts by leading computer scientists presenting positions on the methods, purposes, and functions of computer science. ${ }^{8}$ Using a matrix setup, the groups discuss their assigned text before being reshuffled into five new groups with representatives from all of the original five groups. The students share information from their original group, and then comparison and discussion begin.

One of the important topics of discussion in computer science is the relationship between basic research and technological innovation, often phrased as a tension between computer science and software engineering. Historically, this tension is inherent in their discipline and students will discuss how it revolves around different conceptions of the computer's role: Is it a tool to study the science of data, a fundamental model of computation, or is its purpose to train programmers? Students report that after this exercise, they develop a new vocabulary to talk about their own qualifications and better understand the structure of their own curriculum. Using this as an

\footnotetext{
${ }^{8}$ We use texts by recognized authors within the discipline, such as Peter Naur on 'The Science of Datalogy', Peter Denning on 'The profession of IT: Who are we?' and 'The science in computer science', and Ivar Jacobson and Ed Seidewitz 'A new software engineering'. These all originate from the Communications of the ACM, the discipline's main professional journal, which can be a fruitful source of short texts with a combination of disciplinary and philosophical ramifications.
} 
This is a preprint of a paper to appear in a topical collection in the European Journal of Philosophy of Science, on Teaching philosophy of science to Students from Other Disciplines.

introductory exercise stimulates student activity and discussion culture, and sets the stage for discussions about scientific methods and the spectrum of knowledge production from basic research to technological products.

We find that discussion of short texts exemplifying different views on a topic is a good way to train competences that are perceived as relevant to the students. It is in this context also relevant to consider how teaching strategies and evaluation of these competences are aligned (Biggs 1996). Some courses have oral exams and accordingly include more emphasis on training the students to orally present case material in relation to philosophical positions taught in the course. Other courses have a written exam and include writing exercises where students get formative feedback from other students and teachers. In tutorials, we also sometimes use student presentations and role playing as teaching strategies, where students are asked to present (and sometimes defend) a specific position. We have found this particularly useful when teaching ethics, as presenting positions train the students to identify the distinctive features and strengths of specific positions, relate this to similar (more general) positions, as well as to consider weaknesses and counterarguments. We emphasize that our evaluation of their oral or written exam will value their ability to present a given topic from multiple perspectives, rather than to merely describe one position or express their own opinions. Our view here resonates with other literature in science education emphasizing a shift of focus in assessment from "declarative statements" to “interpretative analysis" and other competences higher on Bloom's taxonomy (Allchin 2011; Biggs and Tang 2007).

We hope that our case examples give an impression of how cases can be selected and used in teaching of philosophy of science to science students. A final point: our cases also illustrate the diversity of text material that can be included in the curriculum. While it is no doubt useful to keep developing good textbooks in philosophy of science, we often use textbook material in combination with papers in contemporary philosophy of science, scientific publications, policy documents, and news media. Aside from being motivating for students to read, exposing the students to a variety of materials can promote critical evaluation of sources, for which they often lack explicit training. Moreover, letting students identify and compare the arguments expressed in different texts can help them develop competences they will need in future projects, such as the ability to identify, analyze, and evaluate arguments against the strength of supporting evidence.

\section{Concluding remarks}


This is a preprint of a paper to appear in a topical collection in the European Journal of Philosophy of Science, on Teaching philosophy of science to Students from Other Disciplines.

The focus on teaching philosophy of science of relevance to future scientists entails a number of considerations, not only about which philosophical dimensions to include but also about how to teach them. The internal development of and debate within the academic field of philosophy of science, which in many places structures the teaching of philosophy of science in ways relevant to philosophy students and their needs, is much less relevant to future scientists. Instead, we have highlighted the benefits of case-based teaching, which takes examples closer to students' practices as the starting point for philosophical reflection, and which can promote active learning. It is our experience that science students find case discussions engaging and useful, which is also reflected in their oral and written course evaluations.

We have illustrated our approach through examples of cases we teach and how we use elements in exercises involving adidactic teaching situations where students discuss the cases on their own. To what extent such exercises, and active learning in general, are possible will of course depend on the context of specific courses. One should be aware that constraints on time and resources often impose a tradeoff between student-centered learning and the scope of "contentbased" teaching. Moreover, the number of students is an important factor. Our group teaches more than 1000 science students per year, and we combine active student-centered tutorials (25-30 students) with larger lectures (up to 150-200 students) that naturally are more teacher-structured. Yet, we find that discussion exercises can also benefit the teaching of large classes, and that there are benefits of rethinking the traditional "deductive" approach to teaching philosophy of science. Hence, we prioritize active approaches whenever possible, because we have seen that student outcomes are better if they engage deeply with selected philosophical topics rather than receiving less in-depth coverage of all major debates in philosophy of science.

We have commented on how practice-oriented teaching imposes new requirements on philosophy teachers. In addition to demands regarding interactional expertise, it can be timeconsuming to find relevant cases. We hope that initiatives such as this topical collection can help facilitate a higher degree of international collaboration on the task of finding and developing suitable teaching materials and engaging student exercises.

Ethics statement: Declaration of conflics: none. Ethics approval/informed consent: N/A 
This is a preprint of a paper to appear in a topical collection in the European Journal of Philosophy of Science, on Teaching philosophy of science to Students from Other Disciplines.

Acknowledgements: We would like to thank our students and co-teachers for helping us improve our teaching practices. We are grateful to Kristine Harper for helpful comments to and assistance with copy-editing of a previous version of this paper.

\section{References}

Abd-El-Khalick, Fouad. 2005. Developing deeper understandings of nature of science: the impact of a philosophy of science course on preservice science teachers' views and instructional planning. International Journal of Science Education 27: 15-42.

Andersen, Hanne, David Budtz Pedersen, and Tom Børsen (2018). Videnskabsteori og dannelse. Fra filosofikum til Fagets videnskabsteori. In: Fagets videnskabsteori. Eds. Tom Børsen, David Budtz Pedersen, and Hanne Andersen, pp. 13-32. Copenhagen: Samfundslitteratur.

Allchin, Douglas. 2011. Evaluating knowledge of the nature of (whole) science. Science Education, 95(3): 518-542.

Allchin, Douglas. 2013. Teaching the nature of science. Perspectives and resources. Saint Paul, MN: SHiPS Education Press.

Allchin, Douglas, Hanne M. Andersen, and Keld Nielsen. 2014. Complementary approaches to teaching nature of science: integrating student inquiry, historical cases, and contemporary cases in classroom practice. Science Education 98: 461-486.

Ankeny, Rachel, Hasok Chang, Marcel Boumans, and Mieke Boon. 2011. Introduction: philosophy of science in practice. European Journal for Philosophy of Science 1: 303-307.

Bettencourt, Luis \& Geoffrey West. 2011. A unified theory of urban living. Nature 467: 912-913.

Biggs, John. 1996. Enhancing teaching through constructive alignment. Higher Education, 32(3): 347-364.

Biggs, John, and Catherine Tang. 2007. Teaching for quality learning at university. Maidenhead: Open University Press.

Boniolo, Giovanni, and Raffaella Campaner. 2020. Life sciences for philosophers and philosophy for life scientists. What should we teach? Biological Theory 15: 1-11.

Brousseau, Guy. 1997. Theory of didactical situations in mathematics. Dordrecht: Kluwer.

Brister, Evelyn, and Robert Frodeman (eds.). 2020. A guide to field philosophy: Case studies and practical strategies. New York, NY: Routledge.

Bschir, Karim. 2017. Risk, uncertainty and precaution in science. The Threshold of the Toxicological Concern approach in food toxicology. Science and Engineering Ethics 23: 489-508. 
This is a preprint of a paper to appear in a topical collection in the European Journal of Philosophy of Science, on Teaching philosophy of science to Students from Other Disciplines.

Burian, Richard M. 1977. More than a marriage of convenience: On the inextricability of history and philosophy of science. Philosophy of Science 44: 1-42.

Burian, Richard M. 2001. The dilemma of case studies resolved: The virtues of using case studies in the history and philosophy of science. Perspectives on Science 9: 383-404.

Bursten, Julia and Samantha Finkelstein. 2018. Promoting Cognitive Conflict in Health Care Ethics: Moral Reasoning with Boundary Cases. In M. Cukurova, J. Hunter, W. Holmes, and V. Dimitrova, eds., Practitioner and Industrial Track Proceedings of the 13th International Conference of the Learning Sciences (ICLS18). University College London, London, UK (23-27 June).

Chang, Hasok. 2012a. Beyond case-studies: History as philosophy. In Integrating history and philosophy of science, eds. Seymour Mauskopf and Tad Schmaltz, 109-124. Boston Studies in the Philosophy of Science, vol 263. Dordrecht: Springer.

Chang, Hasok. 2012b. Is water $\mathrm{H}_{2} \mathrm{O}$ ? Evidence, realism and pluralism. Dordrecht: Springer.

Chang, Hasok. 2015. Reductionism and the relation between chemistry and physics. In Relocating the history of science. Essays in Honor of Kostas Gavroglu, eds. Theodore Arabatzis, Jürgen Renn, and Ana Simões, 193-209. Boston Studies in the philosophy and history of science. Cham, Switzerland: Springer.

Crommie, Michael F., Christopher P. Lutz, and Donald M. Eigler. 1993. Confinement of electrons to quantum corrals on a metal surface. Science 262: 218-220.

Collins, Harry M., and Robert Evans. 2002. The third wave of science studies: Studies of expertise and experience. Social Studies of Science 32: 235-96.

Currie, Adrian. 2018. Rock, bone, and ruin: An optimist's guide to the historical sciences. Cambridge, MA: MIT Press.

El-Hani, Charbel N., Nei de Freitas Nunes-Neto, and Pedro Luís Bernardo da Rocha. 2020. Using a participatory problem based methodology to teach about NOS. In Nature of Science in Science Instruction, ed. William F. McComas, 451-483. Cham, Switzerland: Springer.

Entwistle, Noel. 2009. Teaching for understanding at university. Deep approaches and distinctive ways of thinking. Basingstoke: Palgrave Macmillan.

European Commission. 2008. The European Qualifications Framework for Lifelong Learning $(E Q F)$. Luxembourg: Office for Official Publications of the European Communities.

Firestein, Stuart. 2012. Ignorance: How it drives science. New York: Oxford University Press.

Firestein, Stuart. 2015. Failure: Why science is so successful. New York: Oxford University Press.

Forrester, John. 2017. Thinking in cases. Cambridge, UK: Polity Press. 
This is a preprint of a paper to appear in a topical collection in the European Journal of Philosophy of Science, on Teaching philosophy of science to Students from Other Disciplines.

Freeman, Scott, Sarah L. Eddy, Miles McDonough, Michelle K.Smith, Nnadozie Okoroafor, Hannah Jordt, and Mary P. Wenderoth. 2014. Active learning increases student performance in science, engineering, and mathematics. Proceedings of the National Academy of Sciences 111: 8410-8415.

Giere, Ronald N. 1973. History and philosophy of science: Intimate relationship or marriage of convenience? The British Journal for the Philosophy of Science 24: 282-297.

Giere, Ronald N., John Bickle, and Robert F. Mauldin. 2006. Understanding scientific reasoning. Fifth Edition. Belmont, CA: Wadsworth.

Goddiksen, Mads. 2014. Clarifying interactional and contributory expertise. Studies in History and Philosophy of Science Part A 47: 111-117.

Grüne-Yanoff, Till. 2014. Teaching philosophy of science to scientists: why, what and how. European Journal for Philosophy of Science 4: 115-134.

Guttinger, Stephan. 2020. The limits of replicability. European Journal for Philosophy of Science 10: $1-17$.

Hall, Stephen S. 2011. At fault? In 2009, an earthquake devastated the Italian city of L'Aquila and killed more than 300 people. Now, scientists are on trial for manslaughter. Nature 477: 264-270.

Hartikainen, Susanna, Heta Rintala, Laura Pylväs, and Petri Nokelainen. 2019. The concept of active learning and the measurement of learning outcomes: A review of research in engineering higher education. Education Sciences 9: 276. doi:10.3390/educsci9040276

Herreid, Clyde F., Nancy A. Schiller, and Ky F. Herreid (eds.). 2012. Science stories: Using case studies to teach critical thinking. Arlington, VA: NSTA Press.

Hodson, Derek. 2014. Nature of science in the science curriculum. Origin, development, implications and shifting emphases. In International handbook of research in history, philosophy and science teaching, ed. Michael R. Matthews, 911-90. Dordrecht: Springer.

Höttecke, Dietmar, and Cibelle Celestino Silva. 2011 Why implementing history and philosophy in school science education is a challenge: An analysis of obstacles. Science \& Education 20: 293316.

Iser, Wolfgang. 1984. Der Akt des Lesens. 2nd ed. Munich: Wilhelm Fink Verlag.

Jackson, Philip W. 1990/1968. Life in classrooms. New York: Teachers College Press.

Johansen, Mikkel W., and Frederik V. Christiansen (2020). Handling Anomalous Data in the Lab: Students' Perspectives on Deleting and Discarding. Science and Engineering Ethics, 26, $1107-$ 1128 . 
This is a preprint of a paper to appear in a topical collection in the European Journal of Philosophy of Science, on Teaching philosophy of science to Students from Other Disciplines.

Kampourakis, Kostas, and Tobias Uller (eds.). 2020. Philosophy of science for biologists. Cambridge, UK: Cambridge University Press.

Kuhn, T. S. 1962/1970. The structure of scientific revolutions. 2nd ed. Chicago: University of Chicago Press.

Laplane, Lucie, Paolo Mantovani, Ralph Adolphs, Hasok Chang, Alberto Mantovani, Margaret McFall-Ngai, Carlo Rovelli, Elliott Sober, and Thomas Pradeu. 2019. Opinion: Why science needs philosophy. Proceedings of the National Academy of Sciences 116: 3948-3952.

Latour, Bruno. 1987. Science in action: How to follow scientists and engineers through society. Milton Keynes, UK: Open University Press.

Lassen, Tina Harmer, Hanne Frederiksen, Henriette Boye Kyhl, Shanna H. Swan, Katharina M. Main, Anna-Maria Andersson, Dorte Vesterholm Lind, Steffen Husby, Christine Wohlfahrt-Veje, Niels E. Skakkebæk, and Tina K. Jensen. 2016. Prenatal triclosan exposure and anthropometric measures including anogenital distance in Danish infants. Environmental health perspectives 124: 1261-1268.

Leonelli, Sabina. 2018. Rethinking reproducibility as a criterion for research quality. Including a symposium on Mary Morgan: Curiosity, imagination, and surprise: A Symposium on Mary Morgan (Research in the History of Economic Thought and Methodology, Vol. 36B). Emerald Publishing Limited, 129-146. https://doi.org/10.1108/S0743-41542018000036B009

Matthews, Michael R. 1994/2015. Science teaching. The contribution of history and philosophy of science. 2nd ed. New York: Routledge.

Møllerhøj, Jakob. 2015. It-system til varsel af elevfrafald blev øjeblikkeligt standset af gymnasierne, Version2. Online document retrieved from:

https://www.version2.dk/artikel/noejagtig-frafalds-algoritme-blankt-afvist-i-udbredt-gymnasie-it$\underline{320922 .}$.

Nersessian, Nancy J. 1995. Opening the black box: Cognitive science and history of science. Osiris 10: 194-211.

O’Sullivan, David \& Stephen M. Manson. 2015. Do Physicists Have Geography Envy? And What Can Geographers Learn from It? Annals of the Association of American Geographers. 105, 704722.

Pitt, Joseph C. 2001. The dilemma of case studies: Toward a Heraclitian philosophy of science. Perspectives on Science 9: 373-382.

Plasiance, Kathryn S. 2020. The benefits of acquiring interactional expertise: Why (some) philosophers of science should engage scientific communities. Studies in History and Philosophy of Science 83: 53-62.

Potochnik, Anglea, Matteo Colombo, and Cory Wright, C. 2018. Recipes for science: An introduction to scientific methods and reasoning. London: Routledge. 
This is a preprint of a paper to appear in a topical collection in the European Journal of Philosophy of Science, on Teaching philosophy of science to Students from Other Disciplines.

Potochnik, Angela. 2017. Idealization and the aims of science. Chicago: University of Chicago Press.

Powers, John C. 2020. The history of chemistry in chemical education. Isis 111: 576-581.

Price, Michael. 2012. Why science needs applied philosophy. Science Careers, https://blogs.sciencemag.org/sciencecareers/2012/02/why-science-nee.html. Accessed 25 September 2020.

Prince, Michael J. 2004. Does active learning work? A review of the research. Journal of Engineering Education 93: 223-231.

Prince, Michael, and Richard M. Felder, 2006. Inductive teaching and learning methods:

Definitions, comparisons, and research bases. Journal of Engineering Education 95(2): 123-138.

Şara, Nicolae-Bogdan, Rasmus Halland, Christian Igel, and Stephen Alstrup. 2015. High-school dropout prediction using machine learning: A danish large-scale study. In ESANN 2015 proceedings, European Symposium on Artificial Neural Networks, Computational Intelligence, pp. 319-24, Bruges, Belgium.

Scheffler, Israel. 1971. Philosophy and the curriculum. Philosophic Exchange 2: 7.

Soler, Léna, Sjoerd Zwart, Michael Lynch, and Vincent Israel-Jost (eds.). 2014. Science after the practice turn in the philosophy, history, and social studies of science. London: Routledge.

SPSP Mission Statement. Available online: http://philosophy-science-practice.org/about/missionstatement/. Accessed 1 September 2020.

Terry, David R. 2012. The "case" for critical thinking. In Science stories: Using case studies to teach critical thinking, eds. Clyde F. Herreid, Nancy A. Schiller, and Ky F. Herreid, 25-33. Arlington, VA: NSTA Press.

Toumey, Chris. 2009. Truth and beauty at the nanoscale. Leonardo 42: 151-155.

Ulriksen, Lars. 2009. The implied student. Studies in Higher Education 34: 517-532. 